URETEROVAGINAL FISTULA SECONDARY TO A HIGH FORCEPS DELIVERY

By

RAYMOND E. WATKINS, M.D.

Portland, Oregon

From the Department of Gynecology, University of Oregon Medical Sehool, Portland, Oregon

Reprinted from

AMERICAN JOURNAL OBSTETRICS AND GYNECOLOGY

St. Louis

Vol. XVIII, No. 3, P. 361, September, 1929 


\section{URETEROVAGINAL FISTULA SECONDARY TO A HIGH} FORCEPS DELIVERY

By Raymond E. Watkins, M.D., Portland, Oregon

(From the Department of Gynecology, University of Oregon Medical School, Portland, Oregon.)

INJURIES to the ureter occurring in the course of a pelvic operation are quite frequent. In the many reports of such accidents, the cause and prevention of these injuries, as well as the method of dealing with them, have been discussed. An injury to the ureter during labor, however, is extremely rare. One has to search carefully to find any definite record on this subject. Some authors of obstetrics mention that injuries of this type may occur, but with that they dismiss the subject. In a report on this type of injury by Judd,* there were eited but two instances of ureterovaginal fistulas in which the injury was due to childbirth. Judd reports that in a large series of obstetric cases, Markoe had but one ease at the New York Lying-In Hospital. In view of these facts I am sure the following ease report will be of interest.

Mrs. A. M. I., married, aged twenty-four, consulted me on September 10, 1925, concerning a constant loss of urine. This condition began after a diffeult labor, two and one-half months previously. The patient stated that she had pain in the region of the kidneys on both sides, which radiated around to the pelvis. She had had fever and chills nearly every day since the trouble began. Not all of the urine escaped, as the patient stated that she had voided two to four ounces of urine every two or three hours.

The patient was normal throughout her pregnancy and began labor at term on July 4, 1925. After twelve hours she was given an ether anesthetic and high foreens were applied. The delivery was very difficult the patient being under au forceps were applod. The delivery was vory diffeul, the pationt being under au anesthe sery tho and livery oceured in a sm

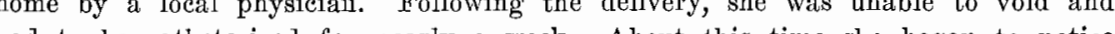
had to be cathetenzed for nearly a week. About this time she began to notice urine on her nightgown, and the bed clothes. She remained in bed three weeks. When she was up and around again she began to have chills and fever nearly every day, which made her so ill that she was unable to carry on her duties about her home.

Her family history is unimportant. Menstruation began at twelve years of age, was of the twenty-eight day type, the flow lasted seven days and was rather profuse with occasional cramp-like pains. She did not have leucorrhea previous to pregnancy. No history of previous urinary disturbance. No symptoms referable to the gastrointestinal tract.

Examination.-The head, neck, chest, and cardiovascular system were negative. The abdomen was soft and flaccid. Palpation in the region of the right kidney

${ }^{*}$ Collected Papers of Mayo Clinic, 8: 1916 and along the course of the right ureter showed moderate tenderness. There was considerable tenderness in the region of the midline of the abdomen just above the pubis. No masses or other pathology was found. Pelvic examination revealed a marked inflammatory condition of the vulva. There was a secon degree perineal laceration well healed. The anterior vaginal wall was relaxed an bulged moderately on straining. The cervix had a wide lateral laceration extending into the left vaginal vault and broad ligament. The uterus was in anterior position and of normal size. There was no evidence of a fistula in the anterior vaginal wall. The bladder was filled with boric solution and no leakage by vagina was observed.

An observation eystoscope was passed. Acute trigonitis was present, but the bladder was otherwise normal, there being no evidence of injury to the bladde walls. The following day a cystoscopic examination was made at the hospital to determine the condition of the kidneys and the ureters. The right ureteral catheter passed without difficulty; the left entered the ureteral orifice, and afte

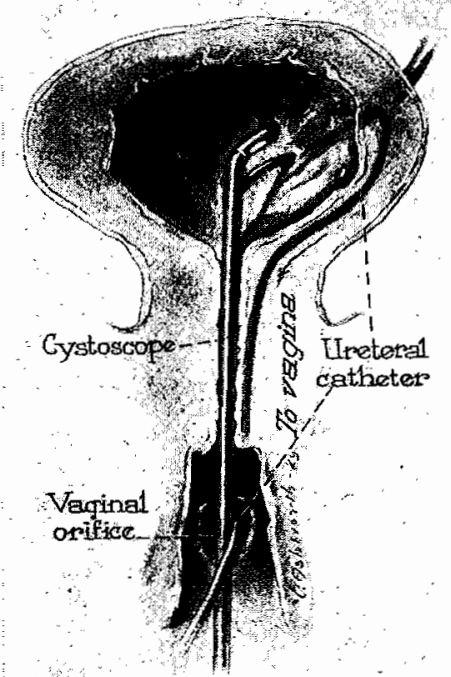

Fig. 1.-Diagrammatic picture showing findings at cystoscopy.

passing about $3 \mathrm{~cm}$. met an obstruction. On being foreed it suddenly overeame the obstruction and passed freely but was found to have come out at the vaginal opening, thereby establishing the diagnosis of fistula of the left ureter at the point where the laceration of the cervix extended into the vaginal wall. (Fig. 1.) An attempt to pass a catheter through this opening up to the kidney was unsuccessful. The function of the right kidney was impaired and cultures of the urine showed a colon bacillus growth. The bladder culture revealed the sam organism.

Upon admittance to the hospital this patient had an afternoon temperature ranging from $100^{\circ}$ to $102^{\circ}$ daily, which dropped to $99^{\circ}$ in the morning. Her pulse was regular ranging from 90 to 110 , with respirations of about 20 . Her blood count showed a red count of 4,420,000, with hemoglobin of 75 per cent. There was a leucocytosis of 16,550 with 81 per cent polymorphonuclear leucocytes. The Wassermann was negative. Urine showed many pus cells, with an occasional bloo cell. 


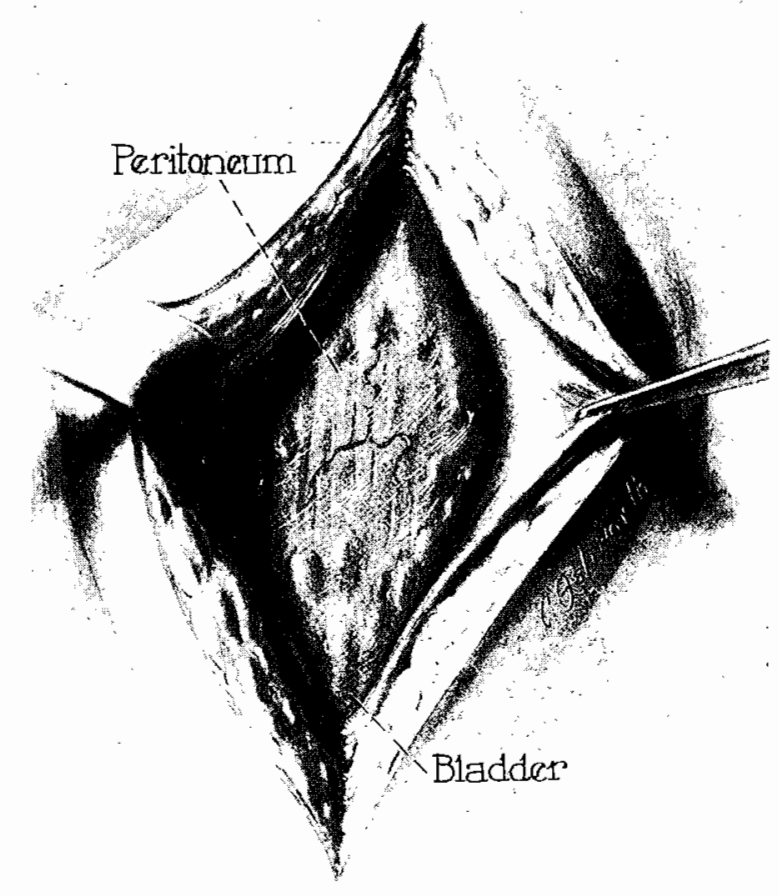

Fig. 2.--Incision carried to peritoneum.

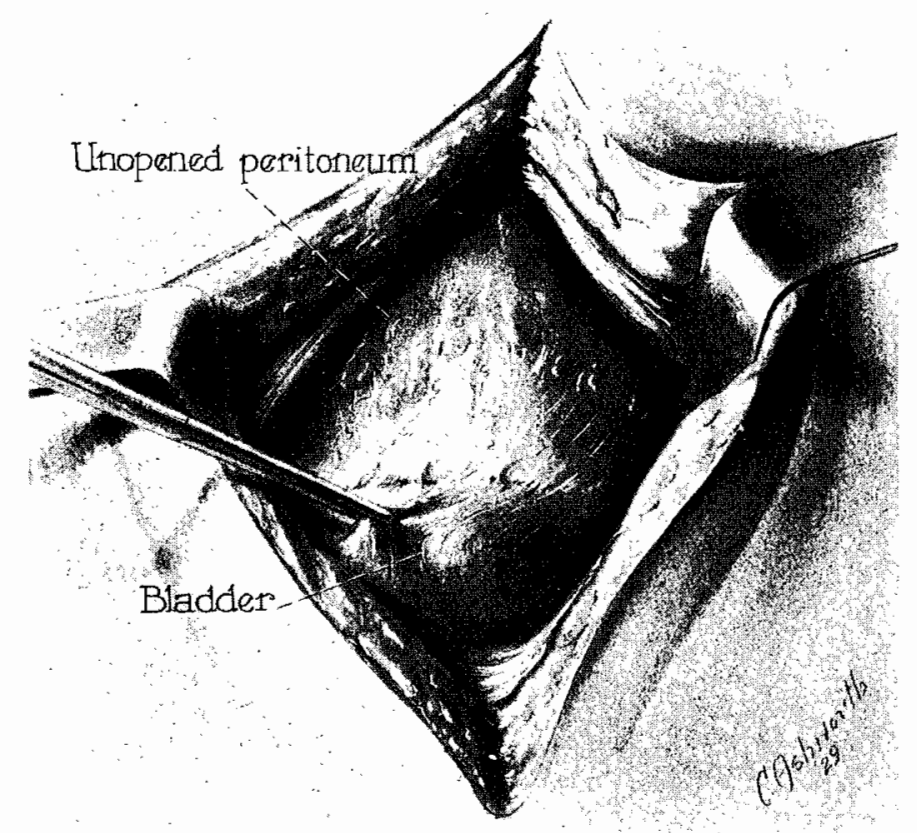

Fig. 3.-Bladder freed from peritoneum.
On September 18, the day of operation, an attempt was made to locate the fistula vaginally with the idea of closure. This failed to expose it sufficiently, beeause of sear tissue and fxation high in the vault of the vagina. It was the decided to make a suprapubie incision and transplant the ureter into the bladder by the extraperitoneal operation described by Judd. On freeing the bladder from the front of the uterus and working laterally in the left wall of the pelvis (Figs. 2 and 3 ), it was found that the ureter was so bound down in a mass of adhesions that it could not be satisfactorily exposed (Fig. 4). An opening was made in the peritoneum and the ureter located where it passes over the bifureation of the iliae vesels ( Fig. 5). It was exposed from this point downward and freed somewhat to a point where it seemed firmly fixed (Fig.6). At this location the

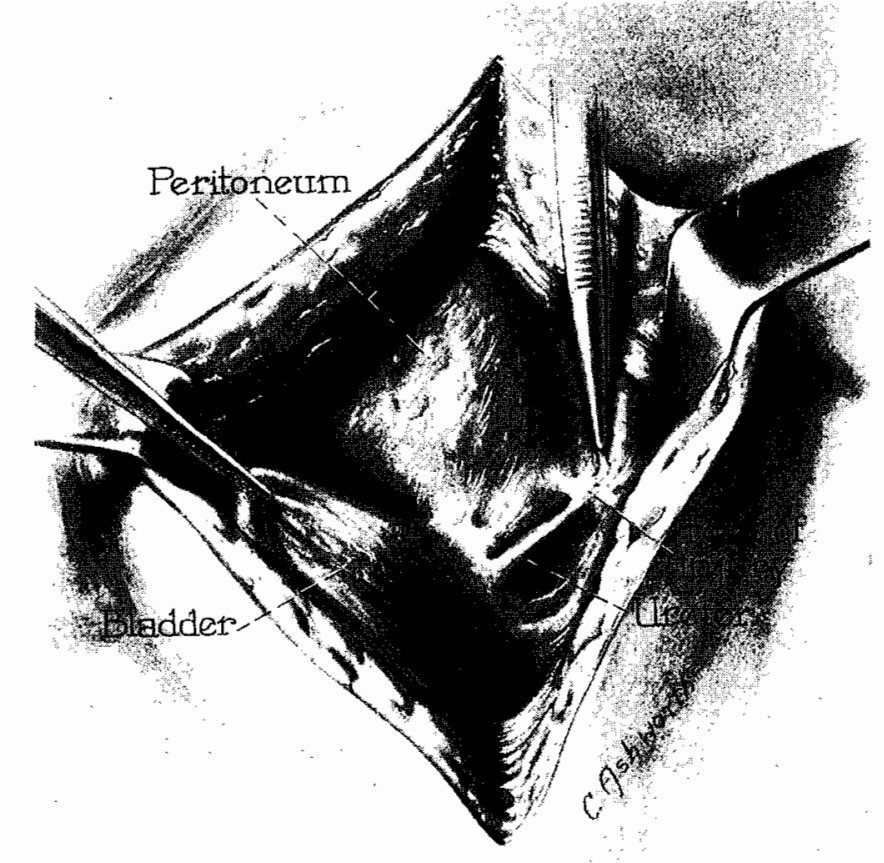

Fig. 4.-Ureter freed to point of injury.

ureter was severed and the eut end transplanted through a small incision int the left lateral wall of the bladder (Fig. 7). The end of the ureter was split, the ureter pushed into the bladder, and the two ends stitched to the mucosa of the bladder (Fig. 7, $a$ and $b$ ). The wall of the bladder was then carefully stitched around the ureter, making an inverted trough (Fig. 7, $c$ and $d$ ). The adjacen perivesical tissue was tacked to the bladder in such a way as to prevent tension on the ureter. Fine chromic eatout was used. A rubber tissue drain was placed down to the side of the tronsplantation closed, and a cigarette drain was left in the abdomen in the middle of the wound. Aside from a rather ireguar temperature, which indoubtelly was due in a

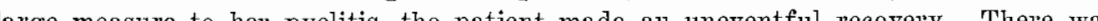
ligh slight serous drainage from the abdominal incision for about three weeks, but this
entirely cleared up and the wound closed. The patient left the hospital in good 
condition and returned to her home. Later a cystoscopy showed the new ureteral orifice, around which was a normal appearing bladder wall. Jets of urine could be seen coming through this opening at regular intervals. At the time the patient left the hospital she had full control of her bladder, and the vaginal leakage had ceased.

The subsequent history of this patient is interesting. August 23, 1926, she again consulted me, stating that she had not menstruated since May 12. Ex. amination showed a pregnancy corresponding to the length of time she had missed her periods. Inasmuch as the eervix was firmy fixed high in the upper left vaginal

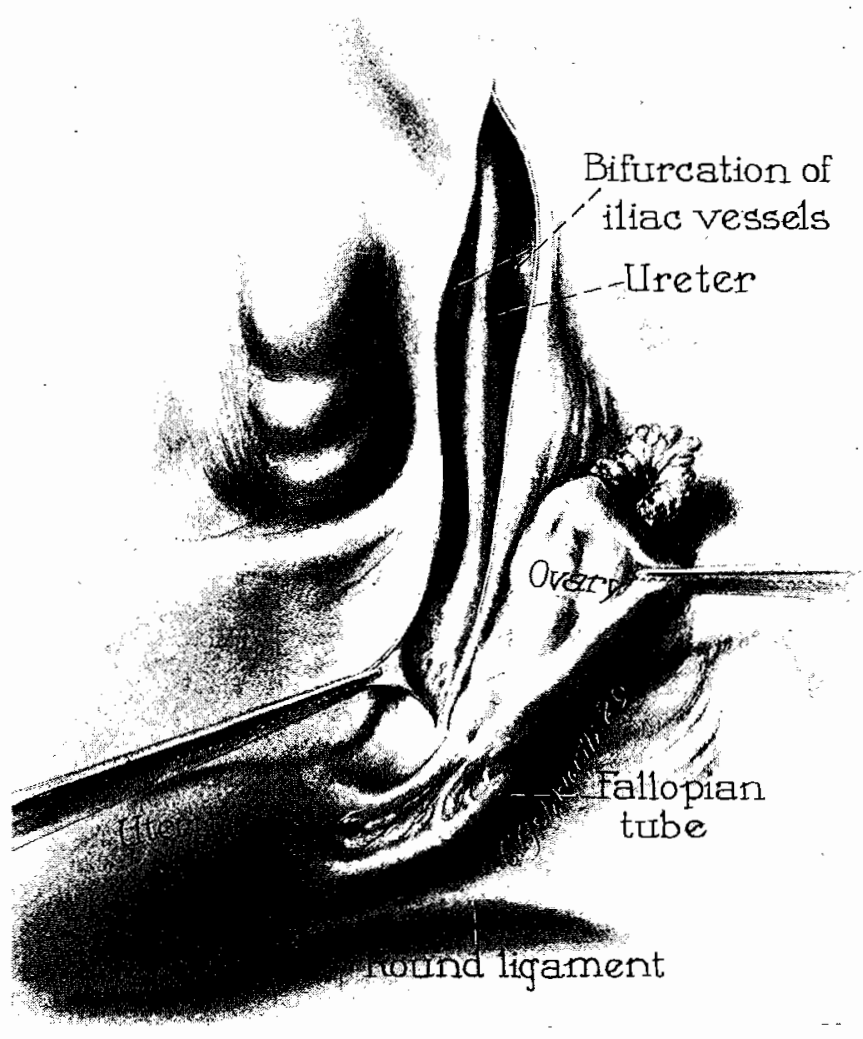

Fig. 5.-Ureter identified from bifurcation of iliacs downward to site of injury.

only a few months previously, much concern was felt about the outeome of this preguancy. Her urine had never been free from pus since her first attack of pinor type of pelvis with a true conjugate of 10 o

The patient was hept under eareful obervation. Tn Norember she had an She then remained free from complications until January 1, When the bag of waters ruptured while she was riding on the train eoning to portand from heme about one hundred miles distant. On her arrival here she was sent to Dmanuel Maternity Hospital and put to bed. She immediately went into labor and after eleven hours gave birtl to a premature baby, weighing four pounds and nine ounces. Her convalescence was uncomplicated and she left the hospital on the fourteentlı day in good con-
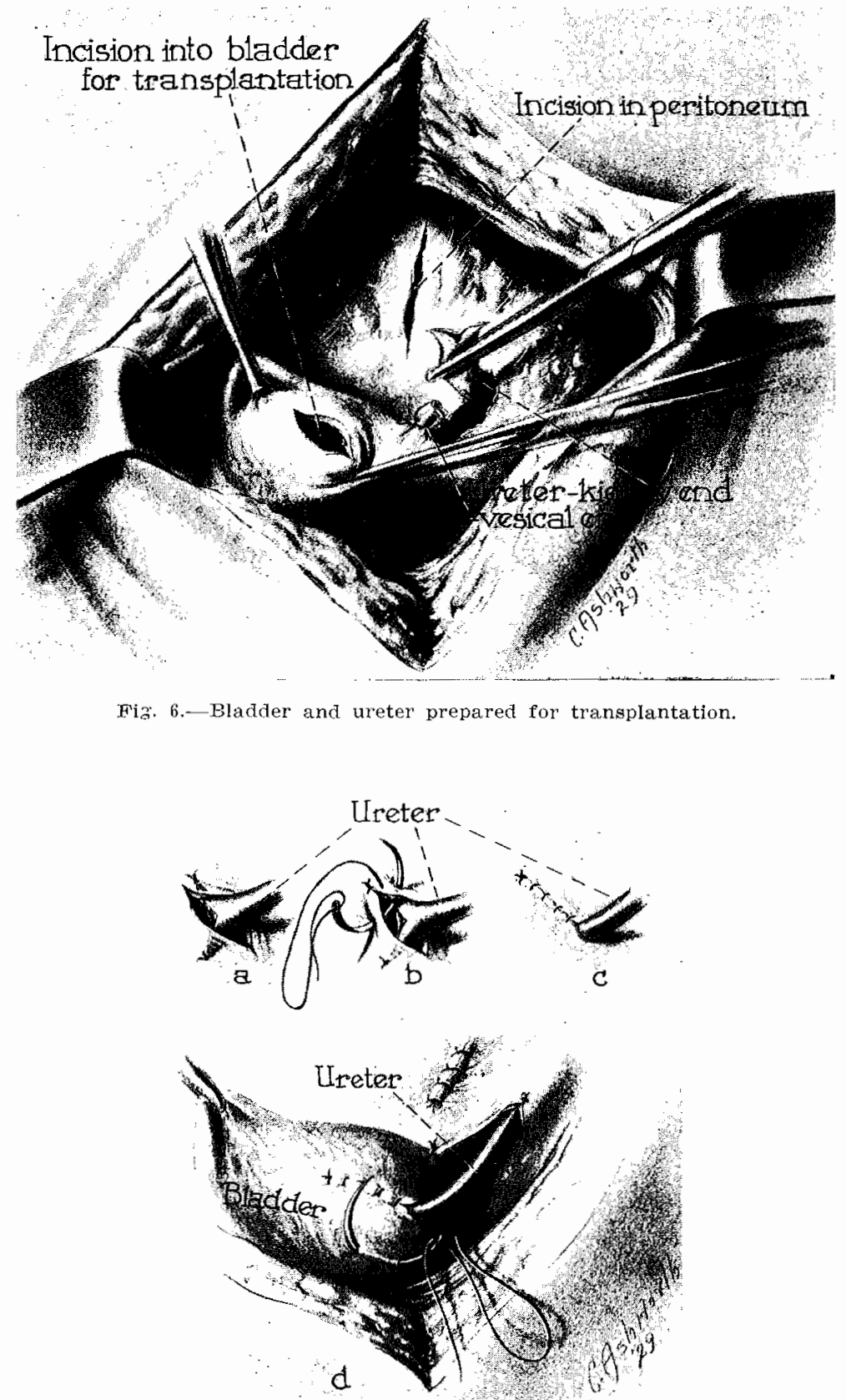

Fig. 7.- - Steps in transplantation of ureter into bladder 
dition. The baby was kept in the ineubator and given mother's milk; it thrived from the beginning. A month later the baby weighed six pounds and was taken home.

Since the delivery, the mother has remained in good health and is able to care for her baby as well as do her housework. The infection of the urinary tract has resisted all types of treatment and still persists, but in mild form.

In the consideration of this case at the time of the operation, it was necessary to make a choice between ureteral transplantation and a nephrectomy. Since the opposite kidney was not only infected but the function impaired as well, a nephrectomy would have been attended with considerable risk. Ureteral transplantation into the bladder is a rational procedure and should be the method of choice in the hands of a competent surgeon.

610 Medical Dental Building. 